\title{
FESTIVAL DE CINE ECUATORIANO KUNTURÑAWI: ANÁLISIS PARA SU CONFORMACIÓN COMO FESTIVAL DE CINE CATEGORÍA A
}

\author{
Kunturñawi ecuadorian film festival: analysis for conformation as \\ film festival a category
}

Francisca A. Carpio-Arias ${ }^{1}$

Galo X. Vásconez-Merino ${ }^{2}$

\section{Resumen}

Los festivales de cine son espacios alternativos de difusión de contenido cinematográfico y de formación de públicos. El Festival de cine ecuatoriano Kunturñawi se realiza desde el 2006 y tiene por objetivo descentralizar la cinematografía realizada en el Ecuador y convertirse en un espacio de reflexión y debate en la región central del país, sobre todo en Riobamba. El objetivo del presente estudio es analizar la séptima edición del mencionado festival con base en los criterios establecidos por Jurado (2018), para valorar la calidad del Kunturñawi y ubicarlo en alguna de las categorías que plantea este autor. Se concluye que el Kunturñawi cumple con 15 de los 18 criterios planteados por Jurado (2018), por lo cual puede ser categorizado en la máxima categoría.

\section{Palabras clave}

Cinematografía, comunicación, festival de cine, espacio alternativo, formación de público.

\section{Abstract}

Film festivals are alternative spaces for the dissemination of cinematographic content and for the training of audiences. The Ecuadorian Kunturñawi Film Festival has been held since 2006 and aims to decentralize the cinematography made in Ecuador and become a space for reflection and debate in the central region of the country, especially in Riobamba. The objective of the present study is to analyze the seventh edition of this festival based on the criteria established by Jurado (2018), in order to assess the quality of the Kunturñawi and place it in one of the categories proposed by this author. It is concluded that the Kunturñawi meets 15 of the 18 criteria set by Jurado (2018), so it can be categorized into the highest category.

\section{Key words}

Cinematography, Communication, film festival, alternative space, audience training

\footnotetext{
${ }^{1}$ Instituto Superior Tecnológico José Ortega y Gasset (Ecuador). Correo electrónico: antito084@hotmail.com.

${ }^{2}$ Universidad Nacional de Chimborazo (Ecuador). Correo electrónico: gvasconez@unach.edu.ec.
} 


\section{Introducción}

Los festivales de cine son espacios alternativos de comercialización y difusión de contenido cinematográfico, así también de formación de públicos, que año a año crecen alrededor del mundo. En países en los que la cinematografía ha logrado un alto grado de industrialización, los festivales además de ser actividades culturales que promueven el turismo, movilizan el ámbito empresarial y se adentran en el contexto de las industrias culturales. "A rasgos generales se trata de acciones involucradas con la cultura, independientemente del ámbito temático que trate, pero no cabe duda que el ser plataforma de directores noveles es la más exclusiva de sus funciones" (Jurado, 2018:85).

El ámbito de los festivales de cine no se restringe a ser una plataforma de lanzamiento de nuevos directores, sino que, desde hace algunas décadas, los festivales se han especializado y encontraron un nicho de público para cada propuesta.

\begin{abstract}
La promoción sería la más visible de sus funciones, la primera y más inmediata tarea que tienen encomendada, pero ni mucho menos la única. Facilitar el acceso de los filmes a los canales de distribución, así como la incorporación a la programación de aquellos otros festivales que, por su carácter estratégico, contribuyan a la mayor visibilización posible del filme en cuestión, favorecer la exhibición futura en salas comerciales, establecer acuerdos de emisión en televisión y plataformas online: éstos serían los principales servicios que un festival puede prestar para facilitar la circulación de las producciones (Redondo, 2015:621).
\end{abstract}

En el caso del Ecuador, hubo iniciativas de festivales de cine de toda índole a través de los años, pero son pocos los que han perdurado en el tiempo, por una serie de dificultades que deben sortear como parte de la gestión cultural; la primera sería la económica, con pocos incentivos por parte de la empresa privada y del Estado; y, en segundo lugar, la misma recepción del público, que no siempre siente atracción hacia estas iniciativas.

En Ecuador, el evento que mayor reconocimiento tuvo a nivel local e internacional es el Festival Internacional de Cine Documental Encuentros del Otro Cine -EDOC, que en el 2019 cumplió su edición número 18. Existen otras propuestas con un corto recorrido como el Festival Internacional de Cine de Guayaquil (cinco ediciones), el Festival Internacional de Cine de Quito (cuatro ediciones) y el Festival de Cine La Orquídea (siete ediciones) que, de a poco, siguen creciendo y tuvieron buena recepción de público y apoyo de muchas instituciones educativas, empresas privadas y financiamiento estatal.
Desde el año 2006, en la sierra centro se realiza el Festival de Cine Ecuatoriano Kunturñawi (en adelante Kunturñawi), constituido por la Fundación Arte Nativo y bajo la dirección de Piedad Zurita, que mantiene su estructura en Riobamba. Este festival tendrá a finales del 2019 su octava edición, bajo el objetivo de "difundiry descentralizar el cine ecuatoriano, la formación de públicos y el encuentro de realizadores con los beneficiarios, además de convertirse en el único espacio a nivel regional de reflexión, debate y formación cinematográfica" (Fundación Arte Nativo, 2018:1).

A este festival se lo considera especializado, porque el ámbito específico de sus proyecciones es el cine ecuatoriano, y es el único de su clase en todo el país. En su página web consta que el festival nace:

Ante la inminente necesidad de difundir la bonanza cinematográfica que se produce en Ecuador, especialmente esta última década, creando espacios para la difusión, valoración del cine ecuatoriano y sus autores, la formación de públicos en la Región Centro del país, mayoritariamente estudiantes de nivel medio y superior, mercados y comunidades indígenas, que en su gran mayoría por primera ocasión han tenido acceso al cine de su país (Festival de Cine Ecuatoriano Kunturñawi, 2019: s/p).

Es necesario que estos espacios mantengan ese surgimiento, como parte de la difusión de la cultura, pero también es preciso que la calidad que ellos persiguen sea la adecuada, tanto en la organización, como en el fortalecimiento de una conveniente programación que incentive al público acudir a las salas de cine.

El presente estudio adopta la propuesta de categorización de festivales de cine de Jurado (2018), que destaca las funciones principales que deben ser atribuidas a un festival de cine y el resultado son 18 condiciones para ubicar a un festival de cine en 4 categorías, a saber: Primera categoría, segunda categoría A, segunda categoría B y tercera categoría. Se analizará la séptima edición del Kunturñawi, llevada a cabo en noviembre del 2018, a fin de encontrar respuesta a cada una de las 18 condiciones y ubicar al festival en la categoría pertinente.

\section{Métodos}

El objetivo del presente estudio es analizar la séptima edición del Kunturñawi para establecer en qué categorización de festivales de cine, planteada por Jurado (2018), se encuentra y con ello valorar su calidad como festival de cine y como encuentro cultural. Para lo cual, se toma como base el informe de cierre presentado al Instituto de Cine y Creación Audiovisual del Ecuador 
ICCA, el proyecto de festival presentado para los fondos concursables de la misma institución y entrevistas no estructuradas en profundidad a integrantes destacados del festival y de la Fundación Arte Nativo.

Con respecto a las entrevistas, se utilizó el formato de entrevista no estructurada en profundidad, con preguntas abiertas, lo que permitió que los entrevistados tengan un abanico de posibilidades para poder expresarse dentro de las preguntas planteadas a cada uno de ellos. Según Del Rincón et al. (1995), esto permite una mayor adaptación a los propios requerimientos investigativos, pero en detrimento requiere de mayor preparación y la información final tiene mayor complejidad.

Se realizaron entrevistas a 10 integrantes del comité organizador del festival en distintos momentos entre diciembre de 2018 y abril de 2019, sistematizando 3 entrevistas por cada miembro del comité. Los miembros tomados en cuenta fueron directora, 2 programadores, 2 administrativos, 1 gestor cultural, 1 comunicador, 1 diseñador, 1 asesor y 1 representante de los acuerdos interinstitucionales.

Se estableció realizar 3 entrevistas a cada miembro del comité, con una duración aproximada de una hora cada entrevista. Las entrevistas más extendidas fueron con la directora del festival y de la Fundación Arte Nativo, Piedad Zurita, por ser integrante fundadora y la única que se mantiene vigente desde la primera edición.

Las entrevistas se realizaron con el objetivo de comprobar y contrastar los criterios utilizados por los expertos mostrados en el marco teórico, además de validar la información revisada en el informe de cierre presentado al ICCA, además porque se creyó importante el criterio interpretativo de cada entrevistado.

De manera global, las preguntas fueron formuladas en aquel sentido y tomando en cuenta las características que debe tener un festival, propuestas por Jurado y para lograr un mayor entendimiento, de primera mano, sobre los antecedentes, la ejecución y evaluación de la séptima edición del Kunturñawi, por lo que las respuestas, de manera general, se encuentran recogidas en cada apartado de las condiciones que deben regir para considerar a un festival en determinada categoría, que a su vez se encuentra incluido en el apartado de resultados.

La ficha de preguntas estuvo constituida por cinco preguntas base, que incluían el aporte personal a la conformación de la séptima edición del festival y, luego, preguntas referentes a la ejecución de las tareas específicas de cada área y el desenvolvimiento que se logró, a modo de evaluación y de análisis de la toma de decisiones. Cabe resaltar que no se realizaron entrevistas externas para el presente estudio, por lo que esto podría considerarse como una debilidad del estudio.

Jurado (2018) destaca que en su estudio realizó 147 entrevistas a distintos integrantes de la cinematografía y el medio audiovisual español y recalca su especificidad a España, por lo que las condiciones podrían variar en otras latitudes. De todas maneras, la aplicación ha sido literal en los 18 puntos que plantea. Apunta a que una categorización de festivales es importante y es necesario que "sirva apoyo al estudio de clasificaciones basadas en argumento de calidad de eventos culturales cinematográficos y en definitiva de eventos que se ubican dentro del fenómeno de las industrias culturales" (Jurado, 2018:136).

\section{Resultados}

\section{El ámbito de los festivales de cine}

Los festivales de cine tienen una historia reciente, intermitente $\mathrm{y}$ en la cual algunos consiguieron posicionarse como grandes espectáculos a los cuales acuden importantes directores y actores del mundo. "Los festivales forman una red de distribución alternativa de cara a Hollywood y al cine mainstream y que funciona, por lo tanto, para corregir las fallas de un sistema de distribución mundial, que se revela desigual" (Elsaesser, 2005 , p. 87). Harbord menciona que "los festivales de cine desde su nacimiento enlazan las culturas del cine dentro de la organización y la materialización de espacio nacional y regional" (2002, p. 61).

Funcionan también como un mercado cinematográfico que permite posicionar géneros dentro del imaginario social, a fin de crear tendencias a nivel global. En el otro extremo están los festivales que se mantienen vigentes, pero que no lograron la suficiente relevancia y a los que les resulta difícil sostenerse por las grandes dificultades económicas y la falta de apoyo al ámbito cultural. En todo caso, los festivales mantienen su vigencia y son cada vez más solicitados en el mundo.

$\mathrm{Su}$ éxito y su permanencia en el tiempo dependen ya no solo de las instituciones locales que ven en ellos una herramienta de promoción, que también, sino sobre todo de haber sabido, precisamente, construir un modelo propio dotado de una identidad específica que haya favorecido su posicionamiento en el mapa mundial de los festivales de cine. En el contexto actual de globalización, su ubicación original en la periferia de la industria no debe constituir una dificultad para lograr dicho posicionamiento si se actúa correctamente en aspectos tales como la presencia en Internet o en la conformación de la red de contactos con los agentes del sector y con 
otros festivales. (Redondo, 2015:626)

Pero los festivales en sí tienen otras connotaciones. Pueden ser entendidos como un elemento discursivo en sí mismos, pues tratan de dar a conocer un punto de vista acerca de cómo cierto sector entiende lo que es el cine, esto a través de la programación concebida como "una estructura dotada de cierta complejidad. En su conformación intervienen elementos tales como los criterios de selección, las secciones (oficiales, paralelas, retrospectivas), los homenajes, las personalidades invitadas de especial relevancia o los premios" (Redondo, 2015:623).

Las proyecciones en los festivales determinan qué películas son distribuidas en distintos espacios culturales y, por lo tanto, a qué películas pueden tener acceso críticos y académicos. Esta última cuestión no es en absoluto desdeñable. Dado que la mayoría de películas no occidentales con las que las audiencias occidentales pueden estar familiarizadas han aparecido en el programa de los festivales, los investigadores tienden a aproximarse a ellas como una invocación nostálgica de los momentos en que las industrias no occidentales fueron «descubiertas» -es decir, descubiertas por los occidentales- en las principales competiciones internacionales (Stringer, 2001, p. 134-135).

La permanencia de un festival depende de varios factores, entre los cuales están aquellas estrategias que se puedan hacer con otros festivales, el seguimiento del público y la relación con los productores y directores cinematográficos, con lo cual los pequeños festivales pueden permanecer en el tiempo. A ello se le debe sumar criterios de calidad que realcen su dimensión como plataformas alternativas de difusión del cine. En este campo se encuentra el Kunturñawi.

En el ámbito académico, se utilizaron varias teorías y análisis para su abordaje, uno de los primeros que surgió es el que definía a los festivales de cine desde su concepto de atractor, "desarrollado por la teoría del caos en el campo de la física. La capacidad de atraer distintos recursos (celebridades, prensa, público)" (Vallejo, 2012, p. 21). A través de este modelo se pretende analizar de manera universal los mecanismos de funcionamiento de los festivales, y para ello utiliza cuatro características con la forma de gestionar recursos del entorno: importación de energía, transformación de la energía, exportación de la energía y el ciclo de operación (la re-energización del entorno), esto quiere decir cómo se administran los recursos que llegan al festival, los tranforma en algo nuevo y los exporta a su vez para renovar el entorno para la siguiente edición (Fischer, 2009).

Existe otro modelo de análisis, que hace foco en la circulación y manifiesta que a la vez que es importante analizarlos en sus características propias, es necesario analizarlos de manera global, como un sistema interconectado. De Valck menciona que se los debe considerar como nodos:

Considero que los festivales de cine pueden ser entendidos como sitios de paso obligatorio, porque son eventos -actores- que han cobrado tanta relevancia en la producción, distribución y consumo de muchas películas que, sin ellos, se derrumbaría una red completa de prácticas, lugares, personas, etc. Estos actores son de vital importancia y constituyen paradas fundamentales para los flujos de la red. (De Valck, 2007, p. 36)

Otras características que suma De Valck es la dimensión experiencial con rituales que se representan y se reproducen en cada entorno, por ejemplo, las alfombras rojas, o la entrega de premios (De Valck, 2007, p. 37).

Un último modelo, trabaja con la idea de espacio de flujos, en la que se entiende a los festivales como mediadores de redes globales de circulación cinematográfica, al que solo acceden las élites para transferir sus intereses a una gran red de crculación de la cultura (De Valck, 2007, p. 41).

\section{Normativa de categorización de festivales de cine.}

Jurado (2018) realiza 147 entrevistas a profesionales del sector cinematográfico español, a fin de crear cuatro categorías en las que se exigen diversas condiciones de calidad para los festivales españoles. Se adoptan 18 condiciones de calidad para analizar la séptima edición del Kunturñawi. Se trata de establecer en qué medida cumple con aquellos parámetros, para finalmente ubicar el festival en la categorización pertinente. Los criterios son los siguientes:

\section{Un certamen podrá formar parte del listado de festivales de cine a partir de la celebración de la quinta edición.}

Para Jurado (2018), el hecho de que un festival supere la quinta edición, asegura una continuidad. Algo con lo que concuerda Piedad Zurita al afirmar que han: "tenido muchas dificultades, sobre todo económicas, pero hemos logrado continuidad, unas veces anual y otras veces bianual, dependiendo de muchos factores, sobre todo económicos" (P. Zurita, comunicación personal, 12 de enero de 2019). Ahora se encuentran más estructurados, con una configuración interna que antes no tenían y el apoyo de muchos programas y proyectos adjuntos que generan espacios de cinematografía de diversa índole, como Guaguas al Cine o Eurocine, todos ellos con el soporte de la Fundación Arte Nativo, que preside Zurita, 
es así que en el 2019 han llegado a la octava edición.

Tabla 1. Historia del Festival de Cine Ecuatoriano Kunturñawi

\begin{tabular}{|c|c|c|}
\hline \#EDICIÓN & FECHA & OBSERVACIONES \\
\hline $\begin{array}{l}\text { Primera } \\
\text { Edición }\end{array}$ & $\begin{array}{c}\text { Noviembre de } \\
2006\end{array}$ & $\begin{array}{l}\text { Seinscriben } 27 \text { películas. Producción } \\
\text { cinematográfica incipiente. Todas } \\
\text { pasan a la Selección Oficial. }\end{array}$ \\
\hline $\begin{array}{l}\text { Segunda } \\
\text { Edición }\end{array}$ & $\begin{array}{c}\text { Noviembre de } \\
2009\end{array}$ & $\begin{array}{l}22 \text { películas en la Selección Oficial } \\
\text { y un aporte económico del Consejo } \\
\text { Nacional de Cine del Ecuador. }\end{array}$ \\
\hline $\begin{array}{l}\text { Tercera } \\
\text { Edición }\end{array}$ & $\begin{array}{c}\text { Noviembre de } \\
2010\end{array}$ & $\begin{array}{l}\text { Ampliación de actividades hacia } \\
\text { Tungurahua y Loja. }\end{array}$ \\
\hline $\begin{array}{l}\text { Cuarta } \\
\text { Edición }\end{array}$ & $\begin{array}{c}\text { Noviembre de } \\
2013\end{array}$ & $\begin{array}{l}\text { Tungurahua, Chimborazo y } \\
\text { Cotopaxi. Firma de convenios } \\
\text { interinstitucionales para talleres y } \\
\text { conversatorios sobre cine. }\end{array}$ \\
\hline $\begin{array}{l}\text { Quinta } \\
\text { Edición }\end{array}$ & $\begin{array}{c}\text { Noviembre de } \\
2015\end{array}$ & $\begin{array}{l}\text { Pastaza, Chimborazo, Cotopaxi } \\
\text { y Tungurahua. } 48 \text { películas en la } \\
\text { Selección Oficial. }\end{array}$ \\
\hline $\begin{array}{l}\text { Sexta } \\
\text { Edición }\end{array}$ & $\begin{array}{c}\text { Noviembre de } \\
2017\end{array}$ & $\begin{array}{l}38 \text { películas en la Selección } \\
\text { Oficial. Asisten } 32 \text { realizadores } \\
\text { cinematográficos de todo el } \\
\text { Ecuador. }\end{array}$ \\
\hline $\begin{array}{l}\text { Séptima } \\
\text { Edición }\end{array}$ & Octubre 2018 & $\begin{array}{l}\text { Asistencia de } 13.221 \text { personas y se } \\
\text { consolida como festival destacado } \\
\text { en la región central del país. }\end{array}$ \\
\hline $\begin{array}{l}\text { Octava } \\
\text { Edición }\end{array}$ & $\begin{array}{c}\text { Noviembre de } \\
2019\end{array}$ & $\begin{array}{l}\text { Se estima que se supere el número } \\
\text { de espectadores de la edición } \\
\text { anterior. } 47 \text { películas en la Selección } \\
\text { Oficial. }\end{array}$ \\
\hline
\end{tabular}

Fuente: elaboración propia con base en el informe final de la séptima edición del festival.

Otro tema importante es el interés consolidado en el tiempo. El Kunturñawi genera expectativa, pues las películas que proyectan no han circulado en cadenas de cines. En el caso de las ciudades de Riobamba y Ambato (aunque a esta última llegan ciertas películas), y en otras ciudades como Guaranda o El Puyo, ni siquiera existe una cadena de cines.

Otra característica del festival es llevar películas a lugares no convencionales, mercados, plazas, barrios y comunidades alejadas de las principales ciudades de las 4 provincias, por lo que allí ya los esperan constantemente para las proyecciones. También Zurita ha realizado convenios con la Universidad Nacional de Chimborazo UNACH, la Escuela Superior Politécnica de Chimborazo ESPOCH, o la Universidad Estatal Amazónica, que incluyen entre sus actividades académicas las proyecciones como actividades paralelas.

\section{Concretar tres categorias en función del presupuesto.}

Jurado (2018), plantea diferenciar 3 categorías en cuanto al presupuesto:
Primera categoría: A partir de 601.000 euros

Segunda categoría: Entre 126.000 y 599.000

Tercera categoría: Hasta 125.000 euros

Se debe tomar en cuenta que España es un país que tiene una potente industria cinematográfica. Sus películas circulan alrededor del mundo y existen políticas públicas de apoyo al arte en todas sus denominaciones. De igual forma, la empresa privada se involucra en el apoyo a los procesos culturales. En el ámbito ecuatoriano, no existe una ley de cine que regule y otorgue incentivos tan grandes para festivales de cine. En el 2018, el Kunturñawi ganó la convocatoria del Instituto de Cine y Creación Audiovisual ICCA, y obtuvo un presupuesto ajustado de 15.000 dólares, sumado a los incentivos que se pudo lograr de empresas privadas e instituciones.

Por lo demás, el 2018 fue un año excepcional para el festival, pues en ediciones anteriores, no se contó con un presupuesto definido, ni el incentivo del Estado para festivales emblemáticos, pues el criterio es que tengan por lo menos 10 ediciones. Para Zurita, el presupuesto por festival fluctúa entre los 2.000 y 5.000 dólares por edición, sin contar apoyos privados en especie (hospedaje, transporte y alimentación).

\section{Cuantía de los premios en la sección competitiva.}

El gran jurado del Kunturñawi entrega estatuillas en reconocimiento a quienes resultan ganadores en las siguientes categorías:

- $\quad$ Largometraje ficción.

- $\quad$ Largometraje documental.

- $\quad$ Cortometraje ficción.

- $\quad$ Cortometraje documental.

- $\quad$ Trabajo universitario.

Además, en el evento de clausura, se entregan menciones de honor para:

$\begin{array}{ll}- & \text { Música. } \\ - & \text { Guión. } \\ \text { - } & \text { Producción. } \\ \text { - } & \text { Investigación. } \\ \text { - } & \text { Dirección. } \\ \text { - } & \text { Fotografía. } \\ \text { - } & \text { Interpretación. } \\ \text { - } & \text { Edición. }\end{array}$

En algunas ediciones se pudo entregar una cantidad monetaria simbólica a las películas ganadoras, pero el 
presupuesto en general es reducido. Por ello desde la séptima edición se creó una estatuilla de diseño propio para el Kunturñawi que se entrega a los ganadores.

\section{Fechas de celebración.}

En casi todas las ediciones, el Kunturñawi ha mantenido noviembre como su mes de proyecciones, exceptuando la séptima edición que se realizó en octubre de 2018. La celebración del festival se corresponde con el cuarto trimestre del año, elegida para emparejar las fechas con la celebración del 11 de noviembre, fecha en que se celebra la emancipación política de la ciudad de Riobamba.

Otros festivales emblemáticos en el país son: Festival Internacional de Cine Documental Encuentros del Otro Cine EDOC, que celebró su edición número 18 en mayo de 2019; el Festival Internacional de cine de Guayaquil, que se celebra en septiembre y en el 2019 ya ha llegado a su quinta edición; el Festival Internacional de cine de Quito, que se celebra en agosto y ya lleva su cuarta edición; y el Festival de cine La Orquídea, que lleva siete ediciones y se celebra en el mes de octubre.

No existe conflicto en fechas, pues la orientación del Kunturñawi desde su concepción ha sido la proyección de cine ecuatoriano y en otros festivales que se dan en el territorio, el cine ecuatoriano pasa a ser una sección del festival o las películas entran en una competencia internacional.

\section{Los festivales de cine deben asegurar la promoción del cine.}

Jurado (2018), propone que los festivales deben cubrir un mínimo de exhibición de cine, de acuerdo con lo siguiente:

Primera categoría: 30 horas.

Segunda categoría, clase A: 20 horas

Segunda categoría, clase B: 15 horas

Tercera categoría: 10 horas

El Kunturñawi, en la séptima edición, se desarrolló en las provincias de Chimborazo, Tungurahua, Pastaza y Bolívar; y en total las proyecciones y actividades duran un mes, teniendo una semana de programación por provincia, lo que asegura contar con más de 30 horas de exhibición de películas. Participaron 40 películas como parte de la selección oficial, 9 cortometrajes universitarios y 6 películas invitadas. Zurita recalcó que cada película se proyectaba un máximo de dos ocasiones.
Tabla 2. Número de películas proyectadas por provincia.

\begin{tabular}{|c|c|}
\hline PROVINCIA & EXHIBICIONES \\
\hline Bolívar & 28 películas proyección-foro \\
\hline Pastaza & 23 películas proyección-foro \\
\hline Tungurahua & 18 películas proyección-foro \\
\hline Chimborazo & 49 películas proyección-foro \\
\hline
\end{tabular}

Fuente: elaboración propia con base en el informe final de la séptima edición del festival

\section{Los festivales de cine nacionales debe promocionar el cine español.}

Jurado (2018) indica que todas las categorías deben proyectar, al menos, un $50 \%$ de producción nacional y para los internacionales y especializados un $33 \%$. El Kunturñawi es un festival que se podría catalogar como especializado, dedicado completamente a promocionar el cine ecuatoriano. Todas las categorías contienen estrictamente material que fue hecho en Ecuador, películas realizadas por ecuatorianos en otras latitudes, o coproducciones con un porcentaje alto de incidencia ecuatoriana.

\section{Los festivales de cine deben promocionar el cine de los nuevos realizadores.}

El Kunturñawi acepta las obras de todos los realizadores y tantas como deseen enviar, no existe una categoría específica para nuevos realizadores u operas primas. En cada categoría conviven tanto cine de autor, como películas realizadas con estrategias del "cine guerrilla" o "cine comunitario", de nuevos realizadores como de quienes ya tienen reconocimiento.

\section{Un festival de cine supone una competición -con o sin cuantía económica-.}

El Kunturñawi difiere de ser una muestra o un concurso, pues el $100 \%$ de las películas que se exhiben están concursando en categorías, y son posibles ganadoras y probables merecedoras de las menciones de honor. En la séptima edición ingresaron al certamen 40 películas seleccionadas: 8 largometrajes documentales; 4 largometrajes ficción; 12 cortometrajes documentales, 13 cortometrajes de ficción, 3 cortometrajes de animación y 9 películas en categoría universitaria.

\section{Los festivales de cine deben favorecer el encuentro de profesionales del sector industrial del cine.}

Jurado (2018) plantea que los festivales de cine deben invitar a personalidades que aporten tanto a nivel cultural 
como industrial para dar charlas, conferencias o cursos, dejando de lado personalidades que tengan tendencia hacia el espectáculo. Propone el siguiente presupuesto para esta tarea:

Primera categoría: $6 \%$ del presupuesto en adelante.

Segunda categoría, clase A: $3 \%$ del presupuesto en adelante.

Segunda categoría, clase B: Hasta el 2\% del presupuesto.

Tercera categoría: Exento, no está obligado a cumplir con este requisito.

Según datos entregados por Piedad Zurita al Instituto de Cine y creación Audiovisual, el Kunturñawi utilizó en su séptima edición, el $15 \%$ de su presupuesto para propiciar el encuentro de profesionales del sector.

\section{Los festivales de cine deben favorecer y difundir especialmente el factor cultural del cine.}

El Kunturñawi desde su concepción se señala que: “El Festival atiende las demandas sobre el acceso a la cultura y la legitimidad de los derechos culturales para ciudadanas/ os" (Fundación Arte Nativo, 2018:3). El factor cultural es fundamental y está en la base del Kunturñawi, mantiene libertad, tanto en la circulación de contenidos, como en la opinión de quienes asisten a dar charlas y talleres.

\section{Un festival tiene que asegurar un aforo mínimo.}

Jurado plantea las siguientes categorías en cuanto al aforo:

Primera categoría: 4.000 butacas/día

Segunda categoría, clase A: 2.000 butacas/día

Segunda categoría, clase B: 1.000 butacas/día

Tercera categoría: 300 butacas/día

El Kunturñawi en su séptima edición tuvo un total de 13.221 asistentes a las proyecciones. Los aforos en general van de las 80 a las 150 butacas por sala de cine, siendo de menor número en las salas alternativas, como por ejemplo en plazas y mercados que tenían 30 butacas.

\section{La asistencia del público es fundamental para un festival de cine.}

Para que la asistencia de público sea mayoritaria, existió un rubro específico para publicidad y un departamento que se encargó de la correcta distribución de las piezas tanto en medios tradicionales, como en alternativos $\mathrm{y}$ digitales de las cuatro provincias en que tuvo lugar el Kunturñawi. "Existía una relación previa con los medios de comunicación que históricamente han venido apoyando al festival, en el marco de la responsabilidad social y amparados en la Ley de Comunicación". (P. Zurita, comunicación personal, 2 de marzo de 2019).

Jurado (2018) plantea que los certámenes deben cubrir un mínimo diario de asistencia a salas, de la siguiente forma:

Primera categoría: $80 \%$ del aforo

Segunda categoría, clase A: $60 \%$ del aforo

Segunda categoría, clase B: $50 \%$ del aforo

Tercera categoría: $33 \%$ del aforo

El festival cumplió con el $80 \%$ del aforo en sus proyecciones.

Tabla 3. Resultados de asistencia a proyecciones por provincia.

\begin{tabular}{|c|c|}
\hline PROVINCIA & TOTALES \\
\hline Bolívar & 3.317 \\
\hline Pastaza & 2.010 \\
\hline Tungurahua & 2.507 \\
\hline Chimborazo & 5.387 \\
\hline TOTAL & $\mathbf{1 3 . 2 2 1}$ \\
\hline
\end{tabular}

Fuente: elaboración propia con base en el informe final de la séptima edición del festival

\section{El festival es libre de cobrar o no la entrada a la proyecciones $u$ otros actos.}

El Kunturñawi desde su primera edición tiene como base fundamental la democratización del cine, por lo tanto, se realiza la gestión con productores y directores para que se puedan proyectar y concursar todas las películas de manera gratuita.

\section{Formación del jurado.}

Jurado, plantea que la conformación del jurado debería ser:

Primera categoría: $100 \%$ de expertos con experiencia o titulación demostrable.

Segunda categoría, A: $70 \%$ de expertos con experiencia o titulación demostrable.

Segunda categoría, B: $50 \%$ de expertos con experiencia o titulación demostrable.

Tercera categoría: $33 \%$ expertos con experiencia o titulación demostrable.

Menciona también que cuando el festival es internacional, debe tener un mínimo de miembros de jurado 
extranjeros, pero el Kunturñawi es estrictamente para cine ecuatoriano. El jurado cambia para cada edición del Kunturñawi. Todos son invitados por su pertinencia en el área cinematográfica, tanto en experiencia como en titulación.

Tabla 4. Jurado de largometrajes séptima edición del Kunturñawi.

\begin{tabular}{|c|l|}
\hline JURADO & \multicolumn{1}{|c|}{ CARGO } \\
\hline Mariana Andrade & $\begin{array}{l}\text { Presidenta de Corporación de } \\
\text { productores de cine y audiovisual del } \\
\text { Ecuador COPAE. }\end{array}$ \\
\hline Diego Falconí & $\begin{array}{l}\text { Cineasta y catedrático de la Universidad } \\
\text { de las Artes UARTES. }\end{array}$ \\
\hline Diego Moreno Garza & Cineasta Mexicano. \\
\hline Maya Cachiguango & $\begin{array}{l}\text { Representante del Instituto de cine y } \\
\text { creación audiovisual ICCA. }\end{array}$ \\
\hline
\end{tabular}

Fuente: elaboración propia.

15. La organización del certamen debe contar con expertos en el ámbito cinematográfico, ya sea a nivel industrial, cultural, $o$ ambos.

El número mínimo exigible para este ámbito es:

Primera categoría: 5 personas.

Segunda categoría, clase A: 3 personas.

Segunda categoría, clase B: 2 personas.

Tercera categoría: 1 persona.

El Kunturñawi se organiza desde Riobamba por la Fundación Arte Nativo, mediante convenios interinstitucionales que permiten la permanencia de las actividades durante un tiempo prolongado y también el delegar actividades a personas específicas, sobre todo profesionales en el ámbito cultural o académico, puesto que las actividades se realizan en gran porcentaje en instituciones educativas. Esto también ayuda en términos económicos y logísticos, pues el desplazamiento constante para la organización a las cuatro provincias, resulta complicado y costoso, así que una vez desarrollada la programación, se activan los convenios y las delegaciones empiezan su trabajo autónomo para llevar a cabo las actividades.
Tabla 5. Co-organizadores de la séptima edición del Kunturñawi por provincia.

\begin{tabular}{|c|c|}
\hline PROVINCIA & ENCARGADO \\
\hline Bolívar & $\begin{array}{l}\text { Lic. Luis Chávez, presidente de la Casa de la } \\
\text { Cultura Núcleo de Bolívar. Lic. Pablo Escorza, } \\
\text { director del Departamento de Cultura del } \\
\text { GAD de Guaranda. Sr. Carlos Guerrón, actor } \\
\text { principal de la película Killa, Ing. Piedad } \\
\text { Zurita, presidenta de la Fundación Arte Nativo }\end{array}$ \\
\hline Pastaza & $\begin{array}{l}\text { Ing. Carlos Garcés, coordinador del } \\
\text { Departamento de Cultura del GAD } \\
\text { de Pastaza. Ing. Lorena Villavicencio } \\
\text { representante de la Casa de la Cultura Núcleo } \\
\text { de Pastaza. Tlgo. Yaku Heredia, integrante } \\
\text { del Comité Organizador del Festival. }\end{array}$ \\
\hline Tungurahua & $\begin{array}{l}\text { Ing. Edgar Merino, Rector ITSB, } \\
\text { Vicerrectora del Instituto, Ing. Piedad } \\
\text { Zurita, presidenta de la Fundación Arte } \\
\text { Nativo y Diego Moreno cineasta mexicano. }\end{array}$ \\
\hline Chimborazo & $\begin{array}{l}\text { Ing. Byron Vaca Rector de la ESPOCH, } \\
\text { Ing. Piedad Zurita, presidenta de la } \\
\text { Fundación Arte Nativo, Dra. Beatriz Viteri } \\
\text { Coordinadora del Convenio ESPOCH-FAN, } \\
\text { Dra. Myriam Murillo, directora de la escuela } \\
\text { de Comunicación-UNACH. Fabián Ramos } \\
\text { y Diego Moreno cineastas internacionales. }\end{array}$ \\
\hline
\end{tabular}

Fuente: elaboración propia con base en el informe final de la séptima edición del festival.

16. Durante todo el año uno o varios responsables de la organización del festival deben supervisar el trabajo anterior a la celebración y darle continuidad con diferentes acciones.

El número estimado es:

Primera categoría: 3 personas.

Segunda categoría, clase A: 2 personas.

Segunda categoría, clase B: 1 persona.

Tercera categoría: 1 persona a tiempo parcial.

En el Kunturñawi existe un equipo de base que realiza actividades inherentes al cine durante todo el año y trabaja como parte de la Fundación Arte Nativo y el Kunturñawi. Si bien es cierto, las reuniones preliminares empiezan a partir del mes de julio en que se presenta la convocatoria para el festival, existe un equipo que trabaja todo el año, conformado por: Kunturñawi.

Piedad Zurita, directora y fundadora del

- $\quad$ Natalia Guashpa Bastidas, administrativa.

- Joselyn Susana Samaniego, gestión cultural.

17. La presencia de los medios de comunicación 
es uno de los referentes más importantes para justificar el cumplimiento de una labor social y cultural.

La manera en que se cumple este punto es por la generación de noticias a nivel local, nacional y autonómico.

Primera categoría: 5 medios de difusión nacional, 5 medios de difusión autonómica, y todos los medios locales.

Segunda categoría, clase A: 4 medio de difusión nacional,medios de difusión autonómica, y todo losmedios locales.

Segunda categoría, clase B:3 medios de difusión nacional, 3 medios de difusión autonómica, y todos los medios locales.

Tercera categoría: todos los medios locales.

El Kunturñawi contrató espacios publicitarios en Facebook, radio, televisión y prensa escrita, además de la impresión de flyers, camisetas, posters y programas de mano. En la séptima edición, fueron varios medios locales y nacionales los que se hicieron eco de las actividades del festival, las cuales fueron detalladas en el punto 12. Los medios nacionales que participaron con su cobertura son:

- $\quad$ Ecuador TV (Noticiero 3 entrevistas, café Tv),

- $\quad$ Radio Pública (3 entrevistas en el noticiero y el programa de Marco Pizza).

El Telégrafo (han auspiciado las dos fases del Festival: la Convocatoria y la ejecución del Festival, a través de la emisión de las cuñas radiales, spot televisivos y cobertura).

- $\quad$ Entrevista en el Noticiero de RTU.

- $\quad$ Tres coberturas en el Diario El Comercio.

- $\quad$ Dos publicaciones en Diario El Universo.

18. Las actividades paralelas completan la oferta cultural y satisfacen la demanda del público que no solo está interesado en las secciones competitivas.

El porcentaje mínimo destinado para las actividades paralelas será de:

Primera categoría: $25 \%$ del presupuesto.

Segunda categoría, clase A: $20 \%$ del presupuesto.

Segunda categoría, clase B: $10 \%$ del presupuesto.

Tercera categoría: exentos.

El rubro para las actividades paralelas del Kunturñawi en su séptima edición fue del $25 \%$ del monto total, asignado para actividades que tuvieron lugar en el lapso de tiempo que duró el festival y otras que se fueron desarrollando durante el año.

Tabla 6. Actividades paralelas de la séptima edición del Kunturñawi.

\begin{tabular}{|c|c|c|}
\hline$\#$ & ACTIVIDAD & DETALLE \\
\hline 1 & $\begin{array}{l}\text { Taller de } \\
\text { Género, familia } \\
\text { y organización a } \\
\text { través del cine }\end{array}$ & $\begin{array}{l}\text { En la Comunidad de Simiatug, con la } \\
\text { participación de estudiantes, maestros } \\
\text { de la UE y organización de Mujeres del } \\
\text { Convento Salesianos }\end{array}$ \\
\hline 2 & $\begin{array}{l}\text { Taller de } \\
\text { Actuación para } \\
\text { Cine }\end{array}$ & $\begin{array}{l}\text { A cargo de Diego Naranjo, en el Auditorio } \\
\text { del GAD Municipal de Guaranda }\end{array}$ \\
\hline 3 & $\begin{array}{c}\text { Taller de Historia } \\
\text { del Cine }\end{array}$ & $\begin{array}{l}\text { Con el cineasta kichwa Miguel Imbaquingo, } \\
\text { en el Auditorio de la Universidad Estatal } \\
\text { Amazónica. }\end{array}$ \\
\hline 4 & $\begin{array}{c}\text { Taller de } \\
\text { Fotografía } \\
\text { Documental }\end{array}$ & $\begin{array}{l}\text { En la Comunidad Unión Base, con el } \\
\text { cineasta kichwa Miguel Imbaquingo } \\
\text { donde se trabajó con la metodología "Cine } \\
\text { de Autor". }\end{array}$ \\
\hline 5 & $\begin{array}{c}\text { Taller de } \\
\text { Fotografía } \\
\text { Documental }\end{array}$ & $\begin{array}{l}\text { Dictado por el cineasta mexicano Diego } \\
\text { Moreno a los estudiantes de Diseño } \\
\text { Gráfico de la ESPOCH. }\end{array}$ \\
\hline 6 & $\begin{array}{l}\text { Taller de Guión } \\
\text { cinematográfico }\end{array}$ & $\begin{array}{l}\text { Dictado por el cineasta mexicano Diego } \\
\text { Moreno Garza, a los estudiantes de Diseño } \\
\text { Gráfico de la UNACH. }\end{array}$ \\
\hline 7 & $\begin{array}{l}\text { Taller de } \\
\text { Narrativa } \\
\text { Audiovisual }\end{array}$ & $\begin{array}{l}\text { Dictado por el cineasta Diego Falconí, } \\
\text { con el apoyo de la Universidad de las } \\
\text { Artes, dirigido a profesionales de la } \\
\text { comunicación y estudiantes de la UNACH. }\end{array}$ \\
\hline 8 & $\begin{array}{l}\text { Taller de Cine } \\
\text { con bajos } \\
\text { recursos }\end{array}$ & $\begin{array}{l}\text { Dictado por el cineasta David Cevallos, } \\
\text { con el apoyo del Grupo Cine de Guerrilla, } \\
\text { dirigido a profesionales del cine y } \\
\text { audiovisual y estudiantes de la Escuelas de } \\
\text { Educación de la UNACH. }\end{array}$ \\
\hline 9 & $\begin{array}{c}\text { Talleres de Video } \\
\text { Arte }\end{array}$ & $\begin{array}{l}\text { Clubes de cine de Colegios, dictado por } \\
\text { el cineasta canadiense Griela Trembley } \\
\text { Pinto. Desde septiembre hasta febrero del } \\
2019\end{array}$ \\
\hline 10 & $\begin{array}{l}\text { Concurso } \\
\text { Intercolegial } \\
\text { de Video Arte } \\
\text { Juvenil }\end{array}$ & $\begin{array}{l}\text { Con la participación de estudiantes de los } \\
\text { Colegios: Maldonado, Miguel Ángel León, } \\
\text { Riobamba, San Vicente de Paúl, Instituto } \\
\text { Bolívar. }\end{array}$ \\
\hline 11 & $\begin{array}{l}\text { Conversatorio } \\
\text { "Retos en el } \\
\text { cine, públicos y } \\
\text { descentralización }\end{array}$ & $\begin{array}{l}\text { Con la participación de los panelistas } \\
\text { Diego Falconí (UARTES), Fabián Ramos } \\
\text { (Colombia) y David Cevallos (España), } \\
\text { Moderadora Martha Bravo. }\end{array}$ \\
\hline 12 & $\begin{array}{l}\text { Lanzamiento de } \\
\text { la Revista No. } \\
1 \text { "Kunturñawi, } \\
\text { Cine } \\
\text { Ecuatoriano", } \\
\end{array}$ & $\begin{array}{l}\text { Con la coordinación de la Gobernación de } \\
\text { Chimborazo. }\end{array}$ \\
\hline 13 & $\begin{array}{l}\text { Cine Móvil } \\
\text { "Maratón de } \\
\text { cortos ganadores } \\
\text { del Kunturñawi } \\
\text { 2006-2017", }\end{array}$ & $\begin{array}{l}\text { Para moradores del Barrio La Estación, } \\
\text { estudiantes universitarios y turistas, en la } \\
\text { Plaza Alfaro. }\end{array}$ \\
\hline
\end{tabular}

Fuente: elaboración propia con base en el informe final de la séptima edición del festival 


\section{Discusión y conclusiones}

Antes de profundizar en la discusión y conclusiones de las categorías planteadas por Jurado, en cuanto a la categorización de festivales, es pertinente realizar un condensado de lo expuesto en el apartado anterior, el cual figura en la tabla 7.

Tabla 7. Condensado de condiciones planteadas por Martín Jurado para la categorización de festivales de cine.

\begin{tabular}{|c|c|c|c|}
\hline NORMAS & CATEGORÍAS & $\begin{array}{l}\text { SEGUNDA } \\
\text { CLASE A CLASE } \\
\text { B }\end{array}$ & TERCERA CATEGORÍA \\
\hline $\begin{array}{l}\text { 1. Inclusión } \\
\text { en el listado } \\
\text { de festivales } \\
\text { de cine }\end{array}$ & & & \\
\hline $\begin{array}{c}2 . \\
\text { Presupuesto }\end{array}$ & & & $\begin{array}{l}\text { Aproximadamente } 7.000 \\
\text { dólares por edición }\end{array}$ \\
\hline $\begin{array}{l}\text { 3. Cuantía en } \\
\text { premios }\end{array}$ & \multicolumn{3}{|c|}{ Se entregan estatuillas a los ganadores } \\
\hline $\begin{array}{l}\text { 4. Fechas de } \\
\text { celebración }\end{array}$ & $\begin{array}{c}\text { Se celebra } \\
\text { dentro del } \\
\text { territorio } \\
\text { nacional en } \\
\text { noviembre. } \\
\text { No choca con } \\
\text { otros festivales } \\
\text { de ninguna } \\
\text { naturaleza }\end{array}$ & & \\
\hline $\begin{array}{l}\text { 5. Promoción } \\
\text { cine, míni- } \\
\text { mos }\end{array}$ & $\begin{array}{l}\text { Cumple más } \\
\text { de } 30 \text { horas de } \\
\text { proyecciones en } \\
4 \text { provincias }\end{array}$ & & \\
\hline $\begin{array}{l}\text { 6.Promoción } \\
\text { cine español } \\
\text { (local) }\end{array}$ & \multicolumn{3}{|c|}{ El Kunturñawi es especializado, solo promociona cine ecuatoriano } \\
\hline $\begin{array}{l}\text { 7. Promoción } \\
\text { cine de } \\
\text { nuevos } \\
\text { directores }\end{array}$ & \multicolumn{3}{|c|}{$\begin{array}{l}\text { Aunque no existe una categoría específica de directores nóveles, se da } \\
\text { prioridad a las películas de nuevos realizadores.v }\end{array}$} \\
\hline $\begin{array}{l}\text { 8. Competi- } \\
\text { ción }\end{array}$ & \multicolumn{3}{|c|}{$\begin{array}{l}\text { El 100\% de las obras que se proyectan están en competición por la } \\
\text { estatuilla Kunturñawi }\end{array}$} \\
\hline $\begin{array}{l}\text { 9. Encuentro: } \\
\text { invitación a } \\
\text { profesionales }\end{array}$ & $\begin{array}{l}\text { Para el } \\
\text { encuentro de } \\
\text { profesionales se } \\
\text { utiliza el 15\% del } \\
\text { presupuesto }\end{array}$ & & \\
\hline $\begin{array}{l}\text { 10. Favorecer } \\
\text { cultura }\end{array}$ & \multicolumn{3}{|c|}{$\begin{array}{l}\text { La difusión de la cultura ecuatoriana está en los objetivos y bases del } \\
\text { festival }\end{array}$} \\
\hline $\begin{array}{l}\text { 11. Aforo } \\
\text { diario }\end{array}$ & & & $\begin{array}{l}\text { En la séptima edición } \\
\text { tuvo un total de } 13.221 \\
\text { asistentes, diariamente } 441 \\
\text { asistentes }\end{array}$ \\
\hline 12. Público & $\begin{array}{l}\text { Se cumplió con } \\
\text { el } 80 \% \text { del aforo }\end{array}$ & & \\
\hline $\begin{array}{l}\text { 13. Cobro de } \\
\text { entradas }\end{array}$ & \multicolumn{3}{|c|}{ El Kunturñawi no cobra entradas para ninguna de sus funciones } \\
\hline $\begin{array}{l}\text { 14. Jurados, } \\
\text { miembros en } \\
\text { festivales } \\
\text { internacio- } \\
\text { nales }\end{array}$ & $\begin{array}{l}\text { El } 100 \% \text { de } \\
\text { jurados tiene } \\
\text { experiencia } \\
\text { o titulación } \\
\text { demostrable }\end{array}$ & & \\
\hline
\end{tabular}

\begin{tabular}{|c|l|l|l|}
\hline $\begin{array}{c}\text { 15. Expertos } \\
\text { en } \\
\text { la organiza- } \\
\text { ción }\end{array}$ & $\begin{array}{l}\text { En la séptima } \\
\text { edición existió }\end{array}$ & & \\
\hline $\begin{array}{c}\text { 16. Profesio- } \\
\text { nales todo el } \\
\text { año }\end{array}$ & $\begin{array}{l}3 \text { personas se } \\
\text { mantienen tra- } \\
\text { bajando durante } \\
\text { todo el año en el } \\
\text { festival }\end{array}$ & & \\
\hline $\begin{array}{c}\text { 17. Medios de } \\
\text { comunica- } \\
\text { ción }\end{array}$ & $\begin{array}{l}6 \text { medios } \\
\text { nacionales. } \\
\text { Todos los } \\
\text { Aparición en: }\end{array}$ & & \\
\hline $\begin{array}{c}\text { 18. Activi- locales. } \\
\text { dades } \\
\text { paralelas }\end{array}$ & $\begin{array}{l}25 \% \text { del presu- } \\
\text { puesto destinado } \\
\text { a } 13 \text { actividades } \\
\text { paralelas }\end{array}$ & & \\
\hline
\end{tabular}

Fuente: elaboración propia

El Kunturñawi se ha convertido en un festival de cine de gran relevancia y connotación en la región central del Ecuador. Empezó como un festival de carácter sencillo solo en la ciudad de Riobamba, pero con el pasar de los años y las ediciones convirtió en una plataforma importante de circulación de filmes ecuatorianos y de su discusión, gracias a la asistencia y presentación de los mismos intervinientes de las películas.

En cuanto al objetivo del presente estudio, que fue analizar la séptima edición del Kunturñawi para establecer su categorización con base al artículo académico de Jurado (2018), se ha expuesto en la Tabla 11 que esta edición ha cumplido con 9 categorías para ser considerado Categoría A y 7 categorías generales, en total 15 de 18 categorías planteadas por Jurado, con lo cual se puede afirmar que el Kunturñawi cumple con las condiciones necesarias para ser considerado Categoría A dentro de los festivales de cine.

Cabe recalcar que el estudio de base fue realizado para tener en cuenta festivales de cine en España, lo cual se recalca en la introducción del artículo científico, pero Jurado también menciona que la categorización se puede replicar para cualquier lugar de España o del mundo, tomando en cuenta las circunstancias especiales de cada lugar en donde se analice, lo cual se ha tomado en cuenta y se concluye que las diferencias son sobre todo en cuanto a lo económico, no llegando siquiera a alcanzar lo mínimo que se plantea para la tercera categoría, pues Ecuador no suele destinar grandes rubros para actividades culturales, ni en el ámbito público ni privado.

Por otro lado, la formación de públicos es algo que todavía está en construcción y tampoco se puede esperar que los festivales de cine congreguen a una multitud de gente como los festivales españoles, ni mucho menos que puedan convertirse en eventos que promuevan el turismo a la región pero, como lo señala Zurita, el fetival cada año tiene mayor alcance $y$, sobre todo, son grandes 
fortalezas los convenios interinstitucionales alcanzados para trabajar con instituciones educativas y universidades, resaltando sobre todo el convenio con la Universidad Nacional de Chimborazo, la Escuela Superior Politécnica de Chimborazo y la Universidad Estatal Amazónica.

Algo fundamental dentro del festival es que está creado para ser un evento de calidad, como se ha visto mediante el análisis de cada categoría, pero también es particular por la prioridad que le da para el acceso democrático al cine, llegando con proyecciones a comunidades indígenas, a plazas y mercados y haciendo funciones al aire libre, en provincias y ciudades que no cuentan o casi, con espacios para poder tener acceso a cine no comercial, mucho menos acceso a cine ecuatoriano; el Kunturñawi lleva ya trece años con este objetivo en mente y está posicionado ya en la región central del Ecuador.

\section{Referencias.}

1. Dayan, D. (2000). Looking for Sundance: The social construction of a film festival. En Moving images, culture and the mind, Bondebjerg $\mathrm{Ib}$ (Ed.), Luton: University of Luton Press. 43-52.

2. De Valck, M. (2007). Film Festivals. From European Geopolitics to Global Cinephilia. Ámsterdam: Amsterdam University Press.

3. Del Rincón, D., Arnal, J., Latorre, A., y Sans, A. (1995). Técnicas de Investigación en Ciencias Sociales. Madrid: Dykinson.

4. Diccionario de Ciencias de la Educación. (1983). Vol. 1. México: Santillana. p. 208.

5. Elsaesser, T. (2005). Cinephilia or the uses of disenchantment. En Cinephilia, movies, love and memory, editado por De Valck, Marijke y Hagener, Malte y Malte Hagener, 27-44. Amsterdam: Amsterdam University Press.

6. Festival de Cine Ecuatoriano Kunturñawi (2019). Historia de Kunturñawi. Recuperado de http://www. kunturnawi.com/

7. Fischer, A. (2009). Conceptualising Basic Film Festival Operation: An Open System Paradigm. Tesis doctoral, Bond University.
8. Fundación Arte Nativo (2018). Informe técnico de cierre de ejecución del proyecto VII Festival De Cine Ecuatoriano Kunturñawi. Riobamba, Ecuador.

9. Hardbord, J. (2002). Film Festivals: Media events and the spaces of flow. En Film Cultures, 59-75. London: Sage.

10. Linares Palomar, R. (2009). La producción cinematográfica. Estrategias de comunicación y distribución de películas. Madrid: Fragua.

11. Miñarro, 1. (2013). Cómo vender una obra audiovisual. Una aproximación a la distribución de contenidos audiovisuales. Madrid: UOC.

12. Jurado Martín, M. (2018). Propuesta de categorización de festivales de cine. Estudio de caso en España. Miguel Hernández Communication Journal, 9 (1), pp. 131 a 160. DOI: http://dx.doi.org/10.21134/mhcj. v0i9.238

13. Jurado, M. y Cortés, L. (2018). Y, ¿para qué sirven los festivales de cine? Estudio sobre las funciones de los certámenes cinematográficos en España (2000-2002). Sphera Pública. Revista de Ciencias Sociales y de la Comunicación, 1(18), 83-103. Recuperado de: http:// sphera.ucam.edu/index.php/sphera-01/article/ view/333.

14. Redondo, F. (2015). Festivales de cine y tendencias de futuro. Un estudio de caso. Opción, 31(1). ISSN: 1012-1587. Recuperado de https://www.redalyc.org/ articulo.oa?id=310/31043005034.

15. Stringer, J. (2001). Global cities and international film festival economy. En Cinema and the city: Film and urban societies in a global context, editado por Mark Shiel y Tony Fitszmaurice, 133-144. Oxford:Blackwell.

16. Subirós, P. (2015). El productor accidental. Barcelona: Anagrama.

17. Vallejo, A. (2012). Festivales de cine documental: redes de circulación cultural en el este del continente europeo. Madrid: Universidad Autónoma de Madrid. 